\title{
Cross protective immune responses in nursing piglets infected with a US spike-insertion deletion porcine epidemic diarrhea virus strain and challenged with an original US PEDV strain
}

\author{
Thavamathi Annamalai, Chun-Ming Lin, Xiang Gao, Xinsheng Liu, Zhongyan Lu, Linda J. Saif* \\ and Qiuhong Wang* ${ }^{*}$
}

\begin{abstract}
We investigated cross-protective immunity of a US spike-insertion deletion porcine epidemic diarrhea virus (PEDV) lowa106 (S-INDEL) strain against the original US PEDV (PC21A) strain in nursing piglets. Piglets were inoculated orally with S-INDEL, PC21A or mock. At 20-29 days post-inoculation (dpi), all pigs were challenged with the PC21A strain. The S-INDEL-inoculated pigs had lower ileal IgA antibody secreting cells, serum IgA and neutralizing antibody titers compared with PC21A-inoculated pigs. No pigs in the PC21A-group developed diarrhea, whereas 81 and 100\% of pigs in the S-INDEL and mock-groups had diarrhea post challenge, respectively. S-INDEL induced partial protective immunity against the original US PEDV strain.
\end{abstract}

\section{Introduction, methods, and results}

Porcine epidemic diarrhea virus (PEDV) belongs to the Coronaviridae family and causes severe gastroenteritis and high mortality in neonatal piglets [1]. Outbreaks of PEDV in the US starting from 2013 [2] resulted in estimated economic losses of \$ 900 million [3]. PEDV outbreaks were reported in 36 states in the US by the National Animal Health Laboratory Network as of January, 2016 (https://www.aasv.org/Resources/PEDv/PEDvWhatsNew.php). PEDV transmission occurs mainly through the fecal-oral route.

Phylogenetic analysis revealed that the original US PEDV strains were closer to the emerging PEDV strain AH2012 from China than to the classical PEDV strains [4]. Apart from the original US PEDV strains, variants that contain insertions and deletions in the S1 subunit of

\footnotetext{
*Correspondence: saif.2@osu.edu;wang.655@osu.edu
}

Food Animal Health Research Program, Ohio Agricultural Research and Development Center, Department of Veterinary Preventive Medicine,

The Ohio State University, 1680 Madison Ave., Wooster, OH 44691, USA the spike (S) protein similar to the classical PEDV strains have been identified in the US. They were designated as "S-INDEL" PEDV strains, likely resulting from multiple recombination events between the classical and emerging PEDV strains in Asia [4-6]. Infection with S-INDEL strain causes less severe infection and low mortality compared with the original highly virulent US PEDV strains $[7,8]$. The spike protein is a membrane glycoprotein that plays a major role in virulence, receptor binding $[9$, 10], and induction of protective immunity during PEDV infection [11].

Similar to the immunization strategies to control transmissible gastroenteritis (TGE) infection [12], lactogenic immunity is important to reduce morbidity and mortality associated with PEDV infection in neonatal piglets. Specifically, secretory IgA antibodies in colostrum and milk play a critical role in conferring protective immunity against enteric viral infections in suckling piglets [13]. However, once lactogenic immunity is curtailed post-weaning, piglets become susceptible to PEDV. Thus 
active immunization is essential to reduce economic losses associated with PEDV infection in weaned piglets. Vaccination against PEDV was extensively implemented in South Korea [14] and China [15], but with little success after 2010. A lower effectiveness of the vaccines may be associated with the emergence of new variants of PEDV [15]. Therefore effective PEDV vaccines against the emerging PEDV strains are urgently needed, but not yet available. Recently, we reported the mild virulence and partial cross-protection of a US S-INDEL PEDV Iowa106 strain against the original US PEDV PC21A strain in nursing pigs [8]. In this study, systemic and local humoral immune responses were assessed after infection of piglets with an S-INDEL strain (Iowa106) and challenge with the original US PEDV strain PC21A.

All experiments were conducted in accordance with guidelines approved by the Institutional Animal Care and Use Committee (IACUC) at the Ohio State University. Virus inocula of the original US PEDV PC21A (GenBank accession no. KR078299) and S-INDEL PEDV Iowa106 (GenBank accession no. KJ645695) were prepared as described previously [8]. These two PEDV variants share $99 \%$ nucleotide identity at the genomic level. Six large white $\times$ Duroc crossbred pregnant animals were purchased from a specific pathogen free swine herd of The Ohio State University. The experimental design was described in detail in our earlier report [8] and is summarized in Figure 1A. Pig litters were randomly assigned to the following groups: (1) inoculated with S-INDEL Iowa106 and challenged with original US PEDV PC21A (four litters, $n=36$ ); (2) inoculated with original US PEDV PC21A and challenged with the homologous strain (one litter, $n=11$ ); and (3) mock inoculated and challenged with original US PEDV PC21A (one litter, $n=7$ ). Piglets were inoculated with the respective virus inoculum at 3-4 days of age and a subset of pigs [S-INDEL $(n=8)$, original US PC21A $(n=3)$, control, $(n=1)]$ were euthanized at 2-3 weeks post inoculation. The remaining piglets were challenged with US PEDV strain PC21A at 20-29 days post-inoculation (dpi). Rectal swabs were collected to assess the severity of diarrhea and fecal virus shedding. Fecal consistency scores 0, 1, 2 and 3 correspond to normal, pasty, semi-liquid, and liquid feces, respectively, with scores of $\geq 2$ corresponding to diarrhea. Virus RNA shedding was titrated by TaqMan realtime reverse transcription-PCR (RT-qPCR) as described previously $[5,8]$. Serum samples were collected weekly from piglets and sows to assess PEDV specific antibody

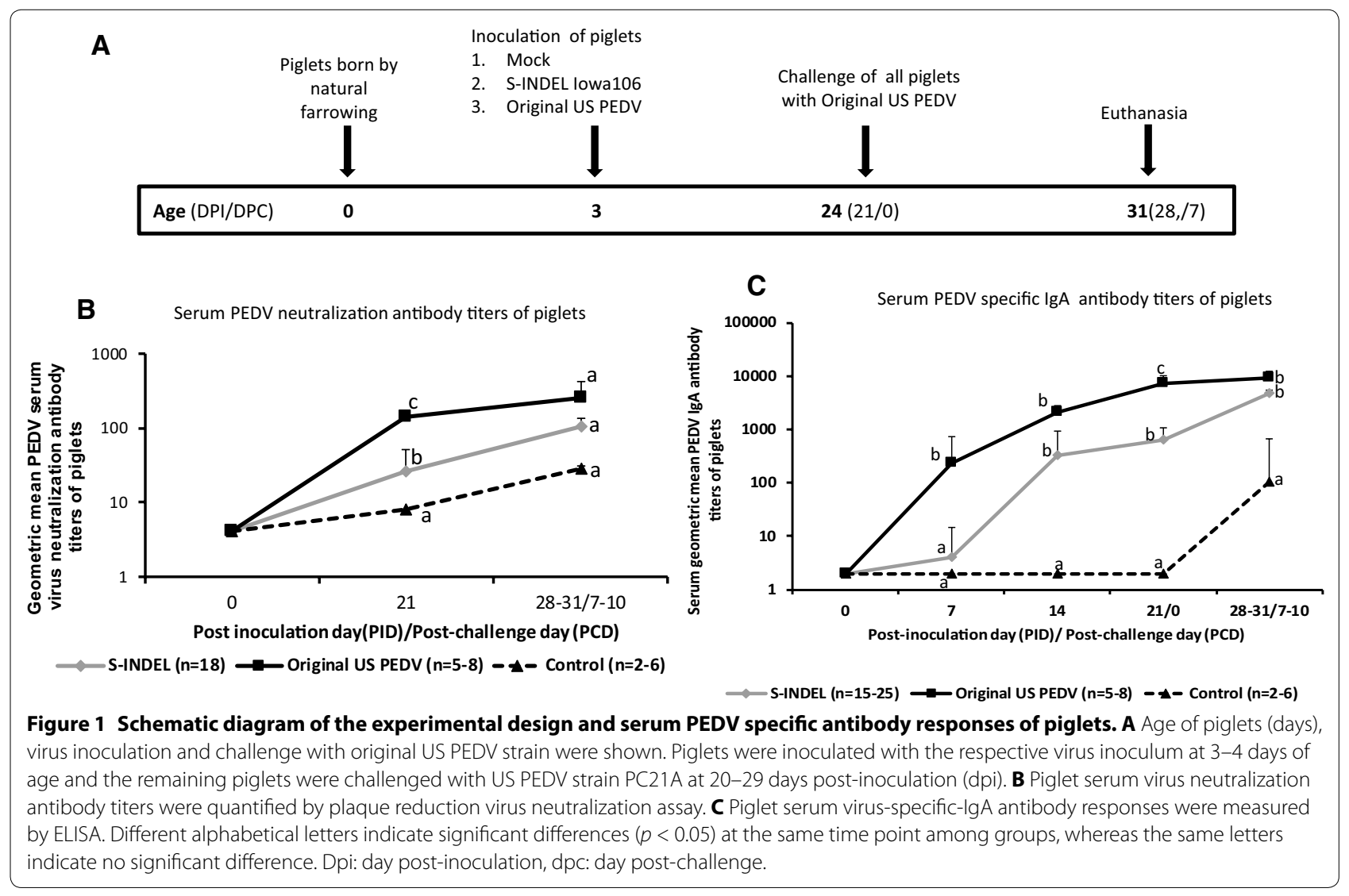


responses. Milk samples were also collected weekly from sows and whey was prepared from milk following protocols described earlier [19] to remove components (fat globules, casein micelles, and cells) that are known to interfere with immunological assays to determine virus specific antibody responses. All remaining piglets [S-INDEL $(n=16)$, original US PC21A $(n=4)$, control, $(n=5)]$ were euthanized at 7 days post-challenge $(\mathrm{dpc})$ and ileal samples were collected to isolate mononuclear cells (MNCs) for enzyme-linked immunospot (ELISPOT) assays (see below) [16].

ELISA was developed for the detection of PEDV specific IgA antibodies. Hyperimmune anti-serum to PEDV used in the ELISA was produced in guinea pigs using repeated immunizations in a standard protocol approved by the IACUC at The Ohio State University. The virus used for immunization of guinea pigs and for ELISA was the tissue culture-adapted original US PEDV strain PC22A (GenBank Accession No. KM392224), which was isolated from the same PEDV outbreak as the PC21A strain [5]. The ELISA for the IgA antibody was adapted from previous standardized protocols $[17,18]$ with slight modifications. Nunc Maxisorp ${ }^{\circledR}$ 96-well plates (NuncImmuno, Denmark) were coated with the guinea pig hyperimmune anti-serum against PEDV in coating buffer (bicarbonate/carbonate buffer, $\mathrm{pH} 9.6$ ) at $37{ }^{\circ} \mathrm{C}$ for $2 \mathrm{~h}$. The plates were washed with phosphate buffered salineTween $(0.05 \%)$ (PBS-T) and blocked with $4 \%$ skim milk (Great Value ${ }^{\mathrm{TM}}$ instant dry milk) diluted in PBS-T overnight at $4{ }^{\circ} \mathrm{C}$. After washing, virus/mock (PEDV-infected Vero cell supernatants/mock-infected Vero cell supernatants prepared as described previously [5]) were added to the wells and incubated at $37{ }^{\circ} \mathrm{C}$ for $2 \mathrm{~h}$. The plates were washed with PBS-T and 4-fold sample dilutions were added to wells. The samples were diluted in $2 \%$ skim milk in PBS-T. After incubating at $37{ }^{\circ} \mathrm{C}$ for $1.5 \mathrm{~h}$, the plates were washed 5 times with PBS-T. Horse radish peroxidase (HRP)-conjugated anti-pig IgA (AbD Serotec, Raleigh, NC, USA) was added and incubated at $37^{\circ} \mathrm{C}$ for $1 \mathrm{~h}$. The plates were washed 5 times and substrate 2,2'-azinobis [3-ethylbenzothiazoline-6-sulfonic acid]diammonium salt) (ABTS) substrate (KPL, Baltimore, MD, USA) was added. The plates were read at $405 \mathrm{~nm}$ after 10 min-incubation at room temperature in the dark. The cut off value was determined as the average of the absorbance of the positive capture of the negative samples +3 times of the standard deviation. The sensitivity and specificity of the ELISA was calculated based on virus neutralizing $(\mathrm{VN})$ antibody titers as gold standard as 100 and $96.6 \%$, respectively.

Whey was prepared from milk following protocols described earlier [19]. Briefly, skim milk was separated by centrifugation of whole milk or colostrum at $2000 \times g$ for $30 \mathrm{~min}$ at $4{ }^{\circ} \mathrm{C}$ and by collecting the middle portion between the cream layer on top and casein layer in the bottom. Whey was prepared by centrifugation of skim milk at $90000 \times g$ for $60 \mathrm{~min}$ at $4{ }^{\circ} \mathrm{C}$. The samples were filtered with $0.45 \mu \mathrm{m}$ filters and stored at $-20{ }^{\circ} \mathrm{C}$.

A plaque reduction virus neutralization assay was performed using the tissue culture-adapted original US PEDV strain PC22A [5]. The protocol was modified slightly from a previously published protocol for transmissible gastroenteritis virus (TGEV) [19]. The sera and whey samples to be tested were heat inactivated for $30 \mathrm{~min}$ at $56{ }^{\circ} \mathrm{C}$. The serum or whey samples to be tested were diluted 2 -fold and the different dilutions $(500 \mu \mathrm{L})$ were mixed with an equal volume of 70 plaque forming units (PFU) of the virus. The mixture was incubated at $37{ }^{\circ} \mathrm{C}$ for $90 \mathrm{~min}$ with gentle rocking. The mixture $(500 \mu \mathrm{L})$ was then added to duplicate wells of monolayers of Vero cells in 6-well plates that had been washed with serum-free medium. The plates were incubated at $37{ }^{\circ} \mathrm{C}$ for 60 min with gentle rocking. The cells were then washed and overlaid with $0.75 \%$ low melting point agarose (SeaPlaque, Lonza, Riverside, PA, USA) in serum free media supplemented with tryptose phosphate broth and trypsin as described for the cultivation of PEDV [5]. The plates were incubated in a humid chamber at $37{ }^{\circ} \mathrm{C}$ for 3 days. The plaques were stained with $0.001 \%$ neutral red solution (Sigma, St. Louis, MO, USA, catalog \# N2889). The plaques were counted and the reciprocal of the highest dilution of a serum or whey sample showing an $80 \%$ reduction in the number of plaques was defined as its virus neutralization titer.

Mononuclear cells (MNCs) were isolated from the lamina propria of the ileum by using previously described methods [20]. The ELISPOT was done by following procedures as described previously [17]. PEDV PC22A strain-infected ( $\geq 80 \%$ of cells PEDV antigen positive by cell culture immunofluorescence assay) and acetonefixed Vero cells in 96-well plates were used as antigens for ELISPOT. The plates were prepared ahead and frozen at $-20{ }^{\circ} \mathrm{C}$. Fixed cells were thawed and rehydrated by incubation with RPMI (Life Technologies, Carlsbad, CA, USA) supplemented with $8 \%$ fetal bovine serum (FBS) (Atlanta Biologicals, GA, USA) for $5 \mathrm{~min}$ at room temperature. Serial dilutions of MNC $\left(5 \times 10^{3}, 5 \times 10^{4}\right.$ and $\left.5 \times 10^{5}\right)$ were added to duplicate wells of the fixed PEDV PC22Ainfected cell monolayers. Plates were centrifuged at low speed $(50 \times g)$ for 5 min and incubated at $37{ }^{\circ} \mathrm{C}$ with $5 \%$ $\mathrm{CO}_{2}$ overnight. The plates were washed 5 times with PBS$\mathrm{T}$. Antibody production by the antibody secreting cells (ASCs) was detected by incubating with HRP-conjugated anti-pig IgA (AA140P; AbD Serotec) diluted 1:3000 and added at $100 \mu \mathrm{L} /$ well or HRP-conjugated anti-pig IgM (Bethyl laboratories, Montgomery, TX, USA) at 1:500 at 
$100 \mu \mathrm{L} /$ well or biotinylated anti-pig IgG (KPL, Baltimore, MD, USA) at dilution of 1:20 000 at $100 \mu \mathrm{L} /$ well and incubated at $1 \mathrm{~h}$ at $37^{\circ} \mathrm{C}$. For IgG antibodies, the plates were washed and incubated with HRP-conjugated streptavidin (1:10 000) (Roche, Indianapolis, IN, USA) at room temperature for $1 \mathrm{~h}$. The plates were washed and the spots were developed by adding 3,3',5,5'-tetramethylbenzidine (TMB) substrate with $\mathrm{H}_{2} \mathrm{O}_{2}$ membrane peroxidase substrate system (KPL) and counted using a light microscope. Counts were averaged from duplicate wells and were expressed relative to $5 \times 10^{5} \mathrm{MNC}$. PEDV specific IgA and VN antibody titers, antibody secreting cell numbers, and virus RNA shedding titers were compared by one-way analysis of variance (ANOVA). Pig diarrhea rates were compared by Fisher's exact test. A value of $p<0.05$ was considered statistically significant.

Original US PEDV or S-INDEL Iowa106 PEDV inoculation induced complete and partial protection, respectively against the original US PEDV challenge. Post inoculation, $100 \%$ of original US PEDV and S-INDEL Iowa106-inoculated piglets had diarrhea and shed PEDV (Table 1). Mean virus RNA shedding titers were higher during the first and third week post inoculation (15-21 dpi) in the original PEDV-inoculated piglets compared with the S-INDEL Iowa106-inoculated piglets, but no such difference was observed during the second week post-inoculation (Table 1). To examine the development of protective active immunity against the highly virulent PEDV strain, piglets were challenged with the original US PEDV strain. Fecal virus shedding and diarrhea were assessed since they are the major parameters in assessing PEDV infection and the severity of disease as well as protective immunity against the viral strains. Mean virus RNA shedding titers were similarly low and did not differ significantly in both S-INDEL Iowa106 $(6.0 \pm 3.1$ $\log _{10} \mathrm{GE} / \mathrm{mL}$ ) and original US PEDV PC21A-inoculated piglets $\left(6.2 \pm 0.3 \log _{10} \mathrm{GE} / \mathrm{mL}\right)$, but significantly lower than that $(8.7 \pm 0.8 \log 10 \mathrm{GE} / \mathrm{mL})$ of the mock (control)inoculated piglets post-challenge. No pigs $(0 / 4)$ had diarrhea in the original US PEDV PC21A-inoculated piglets compared with $81 \%(13 / 16)$ in the S-INDEL Iowa106and $100 \%(5 / 5)$ in the mock (control)-inoculated piglets at 1-7 dpc (Table 1). No gross and microscopic lesions were observed among the pigs [8].

Serum antibody responses were lower in piglets inoculated with the S-INDEL Iowa106 strain compared with the original US PEDV. PEDV specific serum virus neutralization antibody titers were significantly lower in the S-INDEL Iowa106 group compared with the original US PEDV-inoculated piglets at pre-challenge $(0 \mathrm{dpc})$ (Figure 1B). Similar to VN titers, PEDV specific IgA antibody titers were also lower in the S-INDEL Iowa106-inoculated, compared with the original US PEDV-inoculated piglets pre-challenge (0 dpc) (Figure 1C). Compared with the S-INDEL Iowa106 inoculated piglets, the original US PEDV inoculation of piglets induced higher and more rapid PEDV specific IgA antibody responses by $7 \mathrm{dpi}$ (Figure $1 \mathrm{C}$ ).

Intestinal PEDV specific ASC responses were assessed to examine whether S-INDEL Iowa106 and original US PEDV PC21A strains induced any differential intestinal antibody responses. The S-INDEL Iowa 106 strain induced lower intestinal PEDV specific IgA ASC responses. Virus specific IgA ASC responses were significantly lower in the S-INDEL Iowa106-inoculated piglets compared with the original US PEDV-inoculated piglets at 0 DPC (Figure 2A). No differences in virus specific IgG and IgM ASC responses were observed between S-INDEL Iowa106 and original US PEDV-inoculated piglets pre-challenge (Figure 2A). Likewise, intestinal isotype specific ASCs responses were similar between S-INDEL Iowa106 and original US PEDV-inoculated piglets postchallenge (28-31 DPI/7-10 DPC) (Figure 2B). Further,

Table 1 Fecal consistency scores and fecal PEDV RNA shedding titers in original US PEDV-, S-INDEL PEDV-, and mock (control)-inoculated piglets post inoculation and after challenge with the original US PEDV virus

\begin{tabular}{|c|c|c|c|c|c|c|c|c|c|}
\hline & \multicolumn{3}{|c|}{$\begin{array}{l}\text { Mean fecal PEDV RNA shedding } \\
\text { titers (SD) }\left(\log _{10} \mathrm{GE} / \mathrm{mL}\right)\end{array}$} & \multicolumn{3}{|c|}{ Mean fecal consistency scores (SD) } & \multicolumn{3}{|c|}{ Pig diarrhea rates (\%) } \\
\hline & Control & S-INDEL & Original US PEDV & Control & S-INDEL & Original US PEDV & Control & S-INDEL & Original US PEDV \\
\hline DPI 1-7 & ND & $8.2^{b}(1.1)$ & $9.1^{\mathrm{a}}(1.0)$ & $0^{c}$ & $1.7^{\mathrm{b}}(1.0)$ & $2.4^{\mathrm{a}}(0.5)$ & $0^{\mathrm{b}}$ & $100^{\mathrm{a}}$ & $100^{\mathrm{a}}$ \\
\hline DPI 8-14 & ND & $7.8(1.1)$ & $8.2(0.2)$ & 0 & $0.3(0.5)$ & $0.8(0.9)$ & $0^{\mathrm{b}}$ & $0^{\mathrm{b}}$ & $28^{\mathrm{a}}$ \\
\hline DPI 15-21 & ND & $6.7^{b}(0.9)$ & $8.1^{\mathrm{a}}(0.3)$ & 0 & 0 & 0 & 0 & 0 & 0 \\
\hline DPC 1-7 & $8.7^{\mathrm{a}}(0.8)$ & $6.0^{b}(3.1)$ & $6.2^{b}(0.3)$ & $1.2^{\mathrm{a}}(1.0)$ & $1.1^{\mathrm{a}}(0.9)$ & $0^{\mathrm{b}}$ & $100^{\mathrm{a}}$ & $81^{\mathrm{a}}$ & $0^{\mathrm{b}}$ \\
\hline
\end{tabular}

Fecal viral RNA shedding titers were determined by TaqMan real-time reverse transcription-PCR.

Fecal consistency scores $0,1,2$ and 3 correspond to normal, pasty, semi-liquid, and liquid feces, respectively, with scores of $\geq 2$ corresponding to diarrhea. Values with different letters ( $a, b$ and $c$ ) differ significantly between groups (one-way ANOVA for means and Fisher's Exact test for diarrhea rates, respectively. $p<0.05$ ). SD: standard deviation, ND: not detectable. 

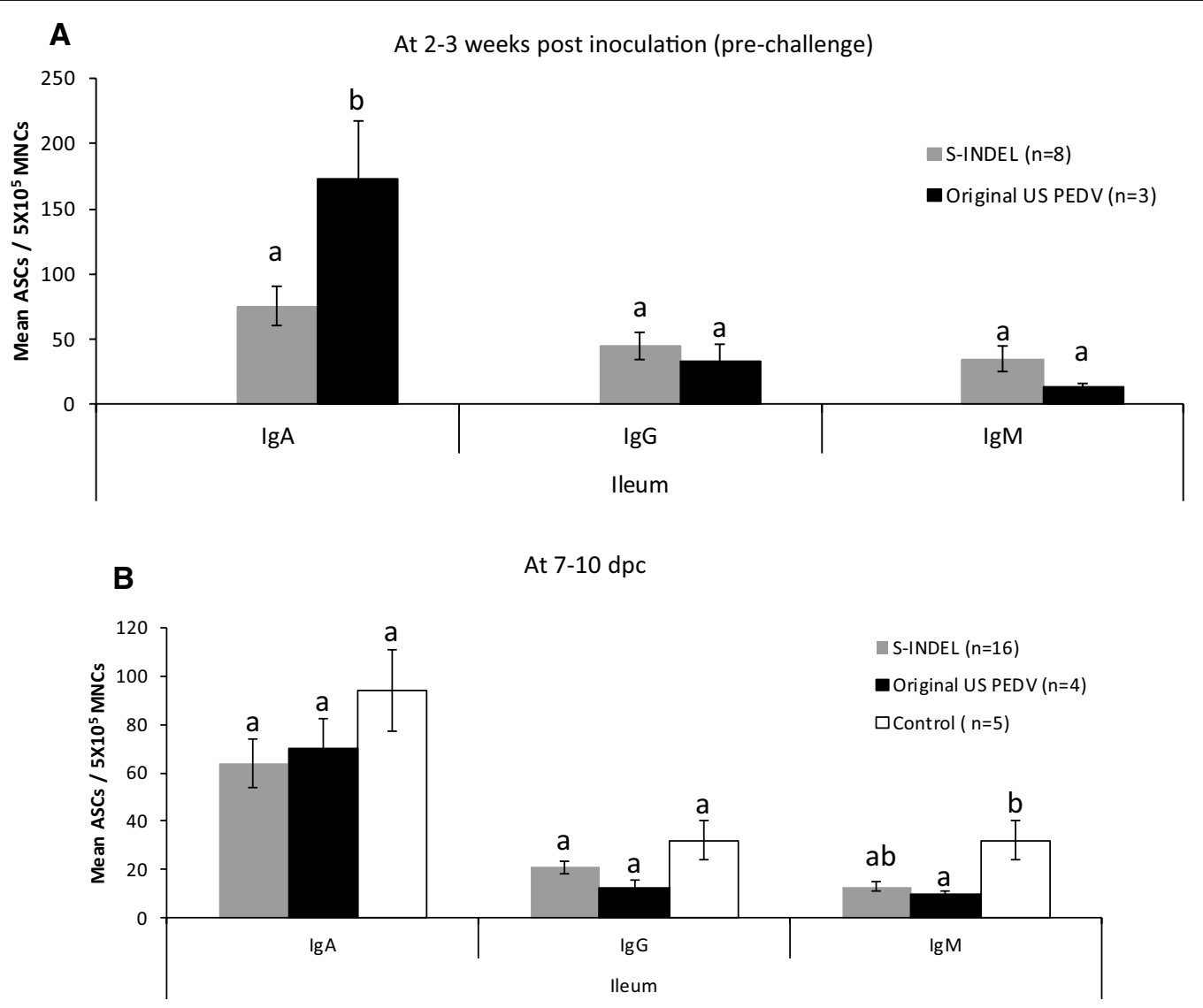

Figure 2 Isotype-specific antibody-secreting cell (ASC) responses to PEDV in ileum of pigs at 2-3 weeks post-inoculation (pre-challenge) (A), and at 7-10 days post challenge (dpc) (B).

the numbers of IgA ASC were consistently higher than the numbers of IgG and IgM ASC for all groups in ileum.

Contact exposure of sows induced virus specific antibody responses in sows. Inoculation of piglets with PEDV caused contact exposure of sows to virus as indicated by fecal virus RNA shedding and the presence of virus specific antibody titers in whey and serum (Figure 3) [8]. Statistics were not done for antibody titers of sows because of $n=1$ for two of the groups. The sows of piglets inoculated with the S-INDEL Iowa106 and the original US PEDV strains showed similar virus neutralization antibody responses in the serum pre-challenge $(0 \mathrm{dpc})$ (Figure 3A). However, whey PEDV neutralization antibody titers and serum PEDV IgA antibody titers were consistently lower in sows of the S-INDEL Iowa106-inoculated piglets compared with the sow of the original US PEDVinoculated piglets (Figures $3 \mathrm{~B}$ and $\mathrm{C}$ ). Further, virus specific IgA antibody titers as determined by ELISA in whey were similar between the sows of piglets inoculated with the S-INDEL Iowa106 and the original US PEDV strains (Figure 3D).

\section{Discussion}

The severity of PEDV infection depends mainly on the age of the piglets [21]. Apart from the age, the strain of PEDV also influences viral pathogenesis. Particularly, studies from our laboratory, as well as from other laboratories, showed that S-INDEL PEDV strains cause less severe infection compared with the original PEDV strains $[7,8]$. However, whether the differences in severity of infection between those PEDV strains have any impact on eliciting protective immunity is unknown. Our results showed that the S-INDEL Iowa106 induced only partial protective immunity against the original US PEDV strain challenge.

Vaccination is considered as an effective method to control PEDV infection in piglets. Mucosal immunity plays a crucial role in conferring protective immunity against enteric infections. Specifically, mucosal antibody responses are correlates of protection against many enteric viral infections. Thus, studying mucosal immunity, such as intestinal antibodies and ASC responses to PEDV strains reveals important information about 

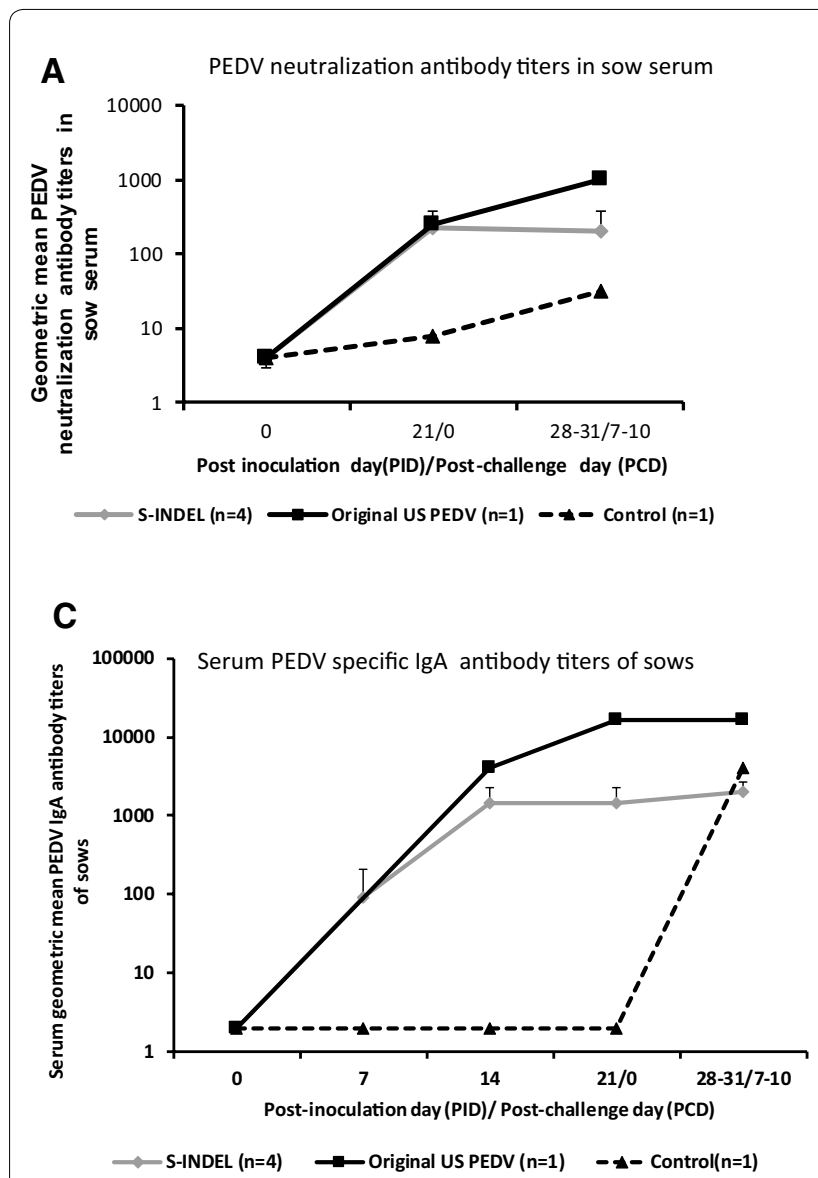

Figure 3 PEDV specific antibody responses of sows in serum and milk whey. Sow serum (A) and milk whey (B) virus neutralization antibody titers were quantified by plaque reduction virus neutralization assay. Sow serum $(\mathbf{C})$ and milk whey $(\mathbf{D})$ PEDV specific IgA antibody responses were quantified by ELISA.
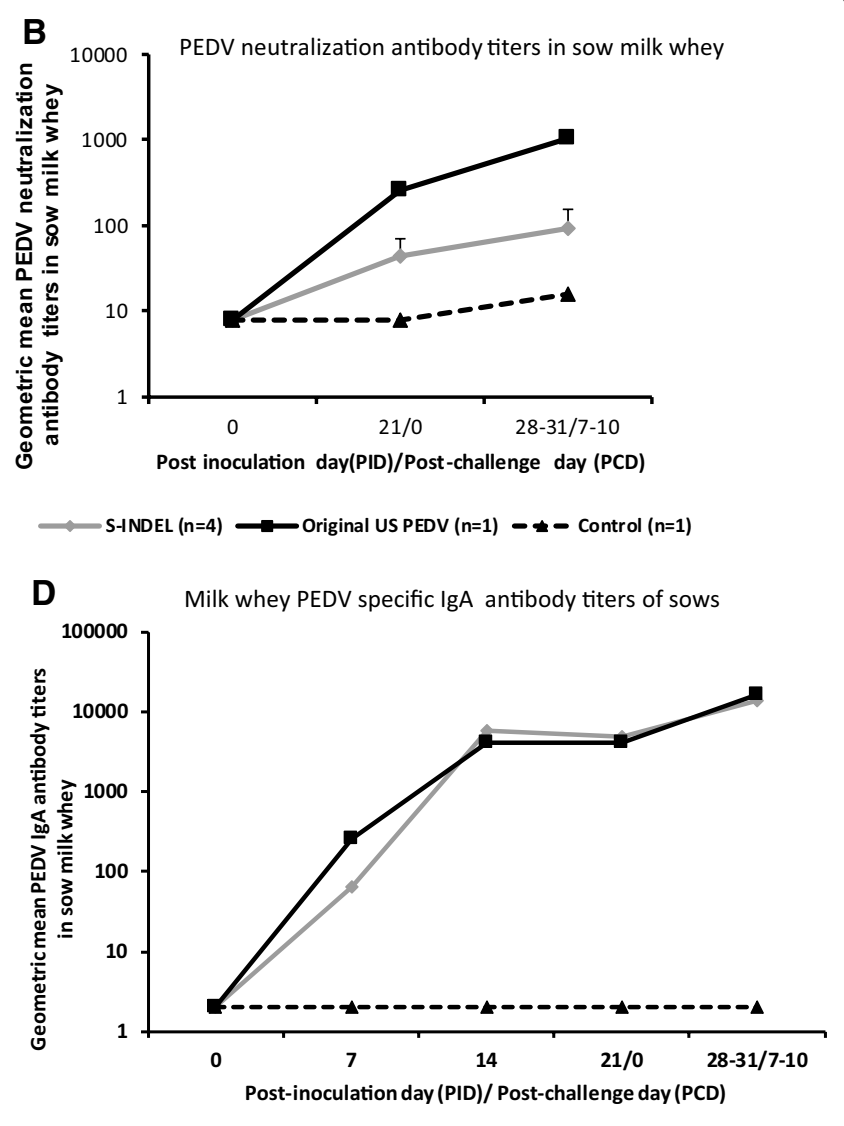

$\longrightarrow$ S-INDEL $(n=4) \quad \rightarrow$ Virulent $(n=1) \quad \ldots-$ Control $(n=1)$
(C) and milk whey (D) PEDV specific IgA antibody responses were

protective immunity against PEDV. Similar to other enteric viral infections such as TGE, porcine respiratory coronavirus [22] and rotavirus [23], in this study both of the PEDV strains also induced predominantly IgA ASC responses in the intestine. Further, single exposure of nursing piglets to the original US PEDV strain or S-INDEL Iowa106 strains resulted in induction of intestinal virus specific IgA ASCs in piglets.

Previous studies showed that the $\mathrm{S}$ protein of PEDV plays an important role in eliciting protective immunity $[24,25]$. Results of this study indicated that mutations in the S protein of S-INDEL Iowa106 strain were associated with reduced systemic and mucosal antibody responses in comparison with responses to the original US PEDV strain. Specifically, ileal virus specific IgA ASCs were significantly lower in the S-INDEL Iowa106inoculated piglets compared with the original US PEDVinoculated piglets pre-challenge. However, the original US PEDV and S-INDEL strains induced similar levels of virus specific IgG and IgM ASCs responses in the ileum.

These results suggest that IgA ASC, but not IgG or IgM ASCs, played a major role in intestinal immunity against PEDV. Further, the S-INDEL Iowa106 induced IgA ASC responses coincided with the partial protection against original US PEDV challenge, as indicated by the significant reduction in virus RNA shedding titers in S-INDELinoculated piglets compared with mock-inoculated piglets. These in vivo results also confirmed our previous in vitro findings in which antisera against S-INDEL Iowa106 neutralized the original US PEDV strain [26]. Similar to our results, sows that were contact exposed to the S-INDEL variant PEDV conferred partial protection to their piglets post challenge with the original US PEDV strain [27].

The milder S-INDEL Iowa106 infection might be a potential reason for a significant reduction in ileal IgA ASC responses in the S-INDEL Iowa106-inoculated piglets compared with the original US PEDV PC21A-inoculated piglets at 14-20 dpi. Further, the original US PEDV PC21A-inoculated, but not the S-INDEL-inoculated 
piglets were completely protected against diarrhea post-challenge. This might be due to the lower level of intestinal IgA ASCs responses in the S-INDEL Iowa106inoculated piglets which might be a possible reason for the failure to induce complete protection against diarrhea post-challenge $(1-7 \mathrm{dpc})$. The specific reason for lower virus-specific antibody responses in the S-INDEL-inoculated compared with the original US PEDV-inoculated piglets is unknown. We speculate that differences in replication kinetics between the PEDV strains might have caused the lower antibody responses in the S-INDEL-inoculated piglets [8]. Specifically, we observed restricted viral infection as indicated by lower percentage of virus infected enterocytes in S-INDEL Iowa106-inoculated piglets compared with original US PEDV PC21A piglets at various post-inoculation time points by immunochemistry staining [8]. Further 3 of the 4 litters of the S-INDEL- inoculated piglets had shorter duration of diarrhea compared with the original US PEDV-inoculated piglets (Table 1). These factors likely have an impact on induction of virus specific antibody responses both mucosally and systemically. Our findings are further supported by an earlier study [28] in which inoculation of virulent PEDV induced complete protection but exposure of piglets to an attenuated strain of PEDV elicited only partial protection against challenge. The authors also hypothesized that differences in viral antigen levels in the intestine between the virulent and attenuated PEDV viruses might have caused differences in induction of protective immunity in piglets [28]. However it should be determined whether a booster dose of S-INDEL Iowa106 induces more complete protection against diarrhea. This idea is supported by our observation that virus specific antibody responses reached comparable levels in both S-INDEL Iowa106 and original US PEDV-inoculated piglets post-challenge (Figures 1, 2). Additionally, attenuated TGEV induced lower levels of intestinal virus specific IgA ASCs compared with virulent TGEV in an earlier study [29]. Thus, differences in virus replication kinetics between the S-INDEL Iowa106 and the original US PEDV PC21A strain might be a reason for lower induction of virus specific IgA ASCs in ileum.

Infection of piglets with the selected PEDV strains also induced virus specific IgA antibody responses in sows through contact exposure followed by infection and virus RNA shedding. Further, induction of virus neutralizing antibody titers in milk whey of the sows also showed that S-INDEL Iowa106 can also induce lactogenic antibodies. Among the sows, milk whey virus neutralization antibody titers at $21 \mathrm{dpi} / 0 \mathrm{dpc}$ were lower in the S-INDEL Iowa106 sows compared with the original US PEDV contact exposed sow. Thus, we speculate that differences in milk whey virus neutralizing antibody titers might also potentially cause differences in protective efficacy between the S-INDEL Iowa106 and original US PEDVinoculated groups.

In summary, Iowa106 strain of PEDV induced a lower magnitude of antibody responses against the original US PEDV strain in pigs compared with that induced by the original US PEDV strain, and resulted in partial protection against challenge with the original US PEDV strain.

\section{Abbreviations \\ S-INDEL: spike insertion and deletion; PEDV: porcine epidemic diarrhea virus; $\mathrm{dpc}$ : days post-challenge; dpi: days post-inoculation; ASCs: antibody secreting cells; ELISPOT assay: enzyme-linked immunospot assay; ANOVA: analysis of variance.}

\section{Competing interests}

The authors declare that they have no competing interests.

\section{Authors' contributions}

QW and LJS designed and supervised the study. TA, QW and LJS wrote the manuscript. TA, CML, XG, XL, ZL and QW performed the experiments. All authors have reviewed the final manuscript. All authors read and approved the final manuscript.

\section{Acknowledgements}

We thank Dr J. Hanson, G. Myers, M. Strother, D. Hartzler, A. Wright, R. Wood and J. Ogg for and animal care assistance, and S.E. Sommer-Wagner, X. Wang, and Marcia V. Lee for technical assistance. The authors thank Drs. J. E. Collins and D. Marthaler, University of Minnesota for providing the S-INDEL PEDV lowa106 strain.

\section{Funding}

This work was partially funded by National Pork Board (Grant \#14-265, QW, Pl; LJS, co-PI). Salaries and research support were provided by state and federal funds appropriated to The Ohio Agricultural Research and Development Center (OARDC), The Ohio State University. The funding agencies did not participate in the design of the study and collection, analysis, and interpretation of data and in writing the manuscript.

\section{Publisher's Note}

Springer Nature remains neutral with regard to jurisdictional claims in published maps and institutional affiliations.

Received: 3 January 2017 Accepted: 17 September 2017

Published online: 06 October 2017

\section{References}

1. Hofmann M, Wyler R (1989) Quantitation, biological and physicochemical properties of cell culture-adapted porcine epidemic diarrhea coronavirus (PEDV). Vet Microbiol 20:131-142

2. Huang YW, Dickerman AW, Piñeyro P, Li L, Fang L, Kiehne R, Opriessnig T, Meng XJ (2013) Origin, evolution, and genotyping of emergent porcine epidemic diarrhea virus strains in the United States. MBio 4:e00737-e00813

3. Paarlberg P (2014) Updated estimated economic welfare impacts of porcine epidemic diarrhea virus (PEDV). http://purl.umn.edu/174517. Accessed 3 Oct 2017

4. Vlasova AN, Marthaler D, Wang Q Culhane MR, Rossow KD, Rovira A, Collins J, Saif LJ (2014) Distinct characteristics and complex evolution of PEDV strains, North America, May 2013-February 2014. Emerg Infect Dis 20:1620-1628

5. Oka T, Saif LJ, Marthaler D, Esseili MA, Meulia T, Lin CM, Vlasova AN, Jung K, Zhang Y, Wang Q (2014) Cell culture isolation and sequence analysis of 
genetically diverse US porcine epidemic diarrhea virus strains including a novel strain with a large deletion in the spike gene. Vet Microbiol 173:258-269

6. Wang L, Byrum B, Zhang Y (2014) New variant of porcine epidemic diarrhea virus, United States 2014. Emerg Infect Dis 20:917-919

7. Chen Q, Gauger PC, Stafne MR, Thomas JT, Madson DM, Huang H, Zheng Y, Li G, Zhang J (2016) Pathogenesis comparison between the United States porcine epidemic diarrhoea virus prototype and S-INDEL-variant strains in conventional neonatal piglets. J Gen Virol 97:1107-1121

8. Lin CM, Annamalai T, Liu X, Gao X, Lu Z, El-Tholoth M, Hu H, Saif LJ, Wang Q (2015) Experimental infection of a US spike-insertion deletion porcine epidemic diarrhea virus in conventional nursing piglets and cross-protection to the original US PEDV infection. Vet Res 46:134

9. Sato T, Takeyama N, Katsumata A, Tuchiya K, Kodama T, Kusanagi K (2011) Mutations in the spike gene of porcine epidemic diarrhea virus associated with growth adaptation in vitro and attenuation of virulence in vivo. Virus Genes 43:72-78

10. Sato T, Takeyama N, Katsumata A, Tuchiya K, Kodama T, Kusanagi K (2011) Mutations in the spike gene of porcine epidemic diarrhea virus associated with growth adaptation in vitro and attenuation of virulence in vivo. Virus Genes 43:72-78

11. Park JE, Cruz DJ, Shin HJ (2011) Receptor-bound porcine epidemic diarrhea virus spike protein cleaved by trypsin induces membrane fusion. Arch Virol 156:1749-1756

12. Oh J, Lee KW, Choi HW, Lee C (2014) Immunogenicity and protective efficacy of recombinant S1 domain of the porcine epidemic diarrhea virus spike protein. Arch Virol 159:2977-2987

13. Saif $L J$, Bohl EH, Gupta RK (1972) Isolation of porcine immunoglobulins and determination of the immunoglobulin classes of transmissible gastroenteritis viral antibodies. Infect Immun 6:600-609

14. Saif LJ, Van Cott JL, Brim TA (1994) Immunity to transmissible gastroenteritis virus and porcine respiratory coronavirus infections in swine. Vet Immunol Immunopathol 43:89-97

15. Park SJ, Song DS, Park BK (2013) Molecular epidemiology and phylogenetic analysis of porcine epidemic diarrhea virus (PEDV) field isolates in Korea. Arch Virol 158:1533-1541

16. Li W, Li H, Liu Y, Pan Y, Deng F, Song Y, Tang X, He Q (2012) New variants of porcine epidemic diarrhea virus, China, 2011. Emerg Infect Dis 18:1350-1353

17. Chattha KS, Vlasova AN, Kandasamy S, Rajashekara G, Saif L (2013) Divergent immunomodulating effects of probiotics on $T$ cell responses to oral attenuated human rotavirus vaccine and virulent human rotavirus infection in a neonatal gnotobiotic piglet disease model. J Immunol 191:2446-2456
18. De Arriba M, Carvajal A, Pozo J, Rubio P (2002) Isotype-specific antibodysecreting cells in systemic and mucosal associated lymphoid tissues and antibody responses in serum of conventional pigs inoculated with PEDV. Vet Immunol Immunopathol 84:1-16

19. Parreño V, Hodgins DC, de Arriba L, Kang SY, Yuan L, Ward LA, Tô TL, Saif LJ (1999) Serum and intestinal isotype antibody responses to Wa human rotavirus in gnotobiotic pigs are modulated by maternal antibodies. J Gen Virol 80:1417-1428

20. Bohl EH, Gupta RK, Olquin MV, Saif $L$ (1972) Antibody responses in serum, colostrum, and milk of swine after infection or vaccination with transmissible gastroenteritis virus. Infect Immun 6:289-301

21. Yuan L, Ward LA, Rosen BI, To TL, Saif LJ (1996) Systematic and intestinal antibody-secreting cell responses and correlates of protective immunity to human rotavirus in a gnotobiotic pig model of disease. J Virol 70:3075-3083

22. Jung K, Annamalai T, Lu Z, Saif LJ (2015) Comparative pathogenesis of US porcine epidemic diarrhea virus (PEDV) strain PC21A in conventional 9-day-old nursing piglets vs. 26-day-old weaned pigs. Vet Microbiol 178:31-40

23. VanCott JL, Brim TA, Lunney JK, Saif LJ (1994) Contribution of antibodysecreting cells induced in mucosal lymphoid tissues of pigs inoculated with respiratory or enteric strains of coronavirus to immunity against enteric coronavirus challenge. J Immunol 152:3980-3990

24. Chen WK, Campbell T, VanCott J, Saif LJ (1995) Enumeration of isotypespecific antibody-secreting cells derived from gnotobiotic piglets inoculated with porcine rotaviruses. Vet Immunol Immunopathol 45:265-284

25. Sun DB, Feng L, Shi HY, Chen JF, Liu SW, Chen HY, Wang YF (2007) Spike protein region (aa 636789) of porcine epidemic diarrhea virus is essential for induction of neutralizing antibodies. Acta Virol 51:149-156

26. Chang SH, Bae JL, Kang TJ, Kim J, Chung GH, Lim CW, Laude H, Yang MS, Jang YS (2002) Identification of the epitope region capable of inducing neutralizing antibodies against the porcine epidemic diarrhea virus. Mol Cells 14:295-299

27. Lin CM, Gao X, Oka T, Vlasova AN, Esseili MA, Wang Q, Saif LJ (2015) Antigenic relationships among porcine epidemic diarrhea virus and transmissible gastroenteritis virus strains. J Virol 89:3332-3342

28. Goede D, Murtaugh MP, Nerem J, Yeske P, Rossow K, Morrison R (2015) Previous infection of sows with a "mild" strain of porcine epidemic diarrhea virus confers protection against infection with a "severe" strain. Vet Microbiol 176:161-164

29. de Arriba ML, Carvajal A, Pozo J, Rubio P (2002) Mucosal and systemic isotype-specific antibody responses and protection in conventional pigs exposed to virulent or attenuated porcine epidemic diarrhoea virus. Vet Immunol Immunopathol 85:85-97

\section{Submit your next manuscript to BioMed Central and we will help you at every step:}

- We accept pre-submission inquiries

- Our selector tool helps you to find the most relevant journal

- We provide round the clock customer support

- Convenient online submission

- Thorough peer review

- Inclusion in PubMed and all major indexing services

- Maximum visibility for your research

Submit your manuscript at www.biomedcentral com/submit
BioMed Central 